\title{
LA BUENAVENTURA DE PRECIOSA
}

Las poesías intercaladas por Cervantes en su obra en prosa constituyen una de las vetas menos trabajadas por la crítica. En conjunto, y con excepciones, ésta ha venido adoptando una actitud caracterizada por las preguntas que su más reciente editor prefiere dejar sin respuesta: "Los versos eran, en efecto, de obligada inserción en toda novela pastoril, ¿ clo eran igualmente en la novela sin más? ¿No constituirían en ella, por el contrario, un estorbo? ¿No son precisamente novela y poesía géneros opuestos?"'1 En el caso particular de La gitanilla, dicha inercia ha quedado rota por el esfuerzo interpretativo de A. G. Forcione ${ }^{2}$, para quien representan una valiosa clave en relación con los más decisivos aspectos intencionales de la novela. Centrada ésta sobre un concepto refinadamente idealizado del matrimonio y el amor conyugal, dentro de un marco de signo erasmista, aclararían dichas

1 Vicente Gaos, introducción a Miguel de Gervantes, Poesías completas, Castalia, Madrid, 1981, t. 2, p. 11.

2 " Here we discover a marriage in which both partners exhibit a good deal of violence and lust, frequently scold and beat [?] one another, and appear to be yoked until death in a conjugal relationship plagued by tyranny, fear, jealousy and adultery. The brief picture of domestic chaos... might have reminded a seventeenth-century reader of Erasmus' popular colloquy on the miseries of unhappy married life, the Uxor Mempsigamos", Cervantes and the Humanist Vision, Princeton University Press, Princeton, 1982, p. 138. "The elusive scene of Preciosa's visit to the lieutenant's 'sterile' house presents, then, through brief but powerful allusion, a fallen world of the court, just as the poem to Doña Clara, which Preciosa recites amid this world, depicts a deeply flawed form of marriage and family life" (ibid. p. 212). Aunque presta alguna atención a estos poemas, no llega a mencionar la buenaventura GeORGES GüNTERT, "La gitanilla y la poética de Cervantes", BRAE, 52 (1972), 107-134. 
piezas los últimos alcances doctrinales de la obra en un serio plano de formulación ilustradora para el lector.

No escapa, como veremos, a esta visión trascendente el tercero de estos poemas, que acoge la buenaventura dicha por Preciosa a la mujer del teniente (sin duda de corregidor) de la villa y corte ${ }^{3}$. Hay que reconocer que dicha pieza se perfila en principio como una salida inesperada, un brusco y casi traumático apearse del "idealismo" con que ha venido etiquetándose a La gitanilla. Es cierto que su heroína pasa a moverse en un terreno al parecer desconcertante y los críticos se hacen los desentendidos, mirando para otra parte, o lamentan, como tiene la sinceridad de confesar Francisco A. de Icaza ${ }^{4}$, el descarrío o tropiezo de Cervantes, incapaz de superar esta vez un irremediable conflicto entre realidad y literatura.

${ }^{3}$ La buenaventura promete un rápido ascenso a corregidor de una ciudad importante. La crítica de los cargos de justicia solía restringirse, por motivos de elemental prudencia, a sus representantes de rasgo inferior, como observa Jean-Marc Pelorson, Les 'letrados' juristes castillans sous Philippe III, Université de Poitiers, 1980, p. 372. Es, pues, erróneo el calificar al teniente de "struggling bureaucrat", como hace Forcione, (op. cit., p. 138). O el tenerlo por "one of the minor town officials", llamado a desempeñar un papel insignificante dentro de un episodio que es, en sí, de relleno (Jennifer Lowe, Two novelas ejemplares, Tamesis Books, London, 1971, pp. 30 y 31). Colmo de ingenuidad el aducir, según hacen algunos, el estado ruinoso de la hacienda real como forma de justificar la ausencia de dineros en casa del teniente. En torno a éste no hay sino inmoralidad y todo el episodio del mismo forma parte, destacada pero no única, del particular menosprecio de corte desarrollado por Cervantes en esta novela.

4 "Y espiritada debía de estar Preciosa cuando improvisaba o adaptaba al caso versos como ios que dedica a la señora Tenienta, en los cuales puede estudiarse hasta qué punto se imponía la realidad sobre el temperamento literario de Cervantes; ya que después de declarar y repetir que la Gitanilla no consintió que 'las que fuesen en su compañía cantasen cantares descompuestos, ni ella los cantó jamás, la hace decir equívocos muy usados en las coplas populares de entonces, pero ajenos del todo al carácter que en ella supone", (Las "Novelas ejemplares" de Cervantes. Sus modelos vivos y su influencia en el arte, Madrid, 1901, p. 106). En la misma vía escandalizada Agustín G. DE AMEZÚA Y MAYO: "Una nota tiene, empero, La gitanilla, excepcional y muy rara en Cervantes, que no hallaremos en el resto de sus Novelas, y que en cierto modo contradice al título de Ejemplares que guardaron las demás, a saber, la mclusión de ciertos pasajes maliciosos, picantes y equívocos. Todos ellos contiénense en la buenaventura que Preciosa lee en la mano de la mujer del Teniente de la Villa, aunque les sirva de excusa el ser imitación del estilo libre y desenvuelto que las gitanas empleaban en las suyas. Verdad es también que en aquellos tiempos tolerábanse más estas licencias en el verso que en la prosa" (Cervantes, creador de la novela corta española, C.S.I.C., Madrid, 1948, t. 2, p. 31). 
El que cabría calificar como enfant terrible de los poemas cervantinos es improvisado por Preciosa al leer la mano de la encumbrada señora:

- Hermosita, hermosita, la de las manos de plata, más te quiere tu marido que el rey de las Alpujarras.

Eres paloma sin hiel; pero a veces eres brava como leona de Orán o como tigre de Ocaña.

Pero en un tras, en un tris, el enojo se te pasa, y quedas como alfiñique, o como cordera mansa.

Riñes mucho y comes poco: algo celosita andas; que es juguetón el Tiniente, y quiere arrimar la vara.

Cuando doncella te quiso uno de muy buena cara; que mal hayan los terceros, que los gustos desbaratan.

$\mathrm{Si}$ a dicha tú fueras monja, hoy tu convento mandaras, porque tienes de abadesa más de cuatrocientas rayas.

No te lo quiero decir...; pero poco importa, vaya: enviudarás, y otra vez, y otras dos serás casada.

No llores, señora mía; que no siempre las gitanas decimos el Evangelio; no llores, señora; acaba.

Como te mueras primero que el señor Tiniente, basta para remediar el daño de la viudez que amenaza.

Has de heredar, y muy presto, hacienda en mucha abundancia; tendrás un hijo canónigo; la iglesia no se señala.

De Toledo no es posible. Una hija rubia y hlanra 
tendrás, que si es religiosa, también vendrá a ser prelada.

Si tu esposo no se muere dentro de cuatro semanas, verásle corregidor de Burgos o Salamanca.

Un lunar tienes, ¡qué lindo! ¡Ay, Jesús, qué luna clara! ¿Qué sol, que allá en las antípodas escuros valles aclara!

Más de dos ciegos por verle Dieran más de cuatro blancas... ¡Agora sí es la risica! ¡Ay, que bien aya esa gracia!

Guárdate de las caídas, principalmente de espaldas; que suelen ser peligrosas en las principales damas.

Cosas hay más que decirte; si para el viernes me aguardas, las oíras, que son de gusto, y algunas hay de desgracia.

Estamos ante la perfecta estilización de un documento folklórico (justo como el ensalmo para el mal de corazón de Andrés, un poco más abajo), testimonio vivo sin duda de lo observado y visto de primera mano ${ }^{5}$. El poema, sin embargo, no va tras la

${ }^{5} \mathrm{El}$ precedente recordado por Cervantes es sin duda el de Eufemia (1567) de Lope de Rueda con una escena muy similar de buenaventura dicha a una dama y su criada. No abundan, al parecer, materiales de comparación dentro de la moderna investigación de campo, pues ni ayudan ni apenas alcanzan la categoría de tal algún repertorio como el de Manuel Díaz Martín, Maldiciones gitanas (Sevilla, 1901). Contemporáneamente destaca el testimonio de tan buen observador popular como Lope de Vega en su comedia de 1603 El arenal de Sevilla. Su protagonista femenina (Lucinda) se hace pasar por gitana y dice más de una "ventura", con uso de la moneda para el trazo de la cruz, etc. En el pasaje más notable finge leer la mano de su rival en amores, pero, lejos del camino seguido por Preciosa, toma por el del común artificio escénico de “"engañar con la verdad", pues al fin y al cabo, no deja de ser una gitana falsificada. Por el contrario, es una gitana auténtica la que en el Aucto del finamiento de Jacob (fechable hacia el tercer cuarto del Xvi) dice la "ventura" a un Bobo con las características fórmulas de adulación introductoria: "Cara de Pazqua florida, / cara de azuzena y rroza, / dónde vaz, perla precioza?" El foco de su profecía es asimismo chocarrero y fácil de creer: "También, porque herez velludo, / zeraz dichozo y honrrado; / zeraz trez vezes cazado / y de todas trez cornudo, / manzo y bienaventurado'" (Leo Rouanet, ed., Códice de autos, farsas y coloquios del siglo xvi, Barcelona, 1901, t. 1, p. 208). A todos se anticipa 
nota ambiental de ningún pintoresquismo o concesión al tema gitanesco, pues nada hay más ajeno a la "pandereta" que la honrada autenticidad del pandero de Preciosa. Lejos de constituir la novela un pretexto para su inserción, se han escrito aquellos versos muy a la mira de aclarar el sentido de la obra y su protagonista bajo un criterio de sobria economía narrativa. Y contra lo que han creído algunos, la novela no es menos, sino tanto más ejemplar por ello.

Frente al carácter convencional y adaptable de este tipo de piezas folklóricas, la buenaventura de la gitanilla destaca por su carácter de improvisación frente al desafío de muy particulares circunstancias. Con su afirmación superadora del formulismo quiromántico al uso, el poema refleja bellamente la doble naturaleza de Preciosa, gitanilla y dama en grados simultáneos y eximios. Aparte de las predicciones de rigor en un recitado de esta clase (amores, hijos, herencias), la pieza se centra sobre una etopeya y hasta cierto punto también prosopografía de doña Clara, sin perder al mismo tiempo de vista a su marido el Teniente. El acto adivinatorio mira a introducir en la obra una nueva e inquietante realidad, que no ahorra los perfiles más negativos e hirientes. La señora, por lo pronto, se retrata como inestable y dada a caprichosas explosiones temperamentales, con los celos como la debilidad más disculpable de su complejo carácter, en el que conviven las especies zoológicas de paloma, leona y tigre. Dibujo de un genio difícil, con el que no es de extrañar que acabe como arma mortífera, llamada a enviar tres o cuatro maridos al otro mundo. Quiere decir que esta semblanza de la pareja cortesana, realizada a través de medios cargados de humor, distará de ser ninguna broma y constituye una de las claves fundamentales para el lector inteligente de La gitanilla.

El poema busca sus fines a través de una retórica muy definida, que lo devana entre figuras muy reconocibles de la expresión burlesca de la época. Tenemos, en primer lugar, afirmaciones como "más te quiere tu marido / que el rey de las Alpujarras". Pero bajo el aspecto de una bella fórmula ponderativa se descubre un absoluto vacío: el esposo no necesitará quererla mucho para ganar la mano al inexistente rey $\operatorname{granadino}^{6}$, pues un amor me-

Gil Vicente con su Farsa das ciganas (hacia 1521), cuya Giralda dice cosas como: "Porné ciento contra treinta / Que de loz piez a la cinta / Tienez la buena ventura"' (Gil Vicente, Obras, Lello \& Irmão, Porto, 1965, p. 646).

6 Las anotaciones de la edición de R. Schevill y A. Bonilla (Novelas exemplares, Madrid, 1922, t. 1) pretenden ver aquí una alusión al reyezuelo de la 
dido por el término de comparación de cero no ha de llegar muy allá para sacar verdadera a la adivinadora. Lo mismo cabe decir de las lagrimillas de cocodrilo ante el anuncio de viudez, siempre eludible con el sencillo expediente de morir ella primero (un sacrificio de Alcestes muy poco verosímil en esta doña Clara), sólo que es también una estrategia de taimado circunloquio para introducir un "te mueras" tras el que acecha al trasluz un valor optativo en cuanto intención del hablante (giro "así te mueras..."). Idéntica jugada con aquella indiscreción acerca del íntimo lunar, que, con empleo de la figura etimológica, es luna y a la vez impúdico sol cuya contemplación desearían, perogrullescos, algunos ciegos. Aunque en este ejemplo hay también su dosis de ambigua malicia, con su abrirse a la perspectiva de alguna celada vida galante de ella, porque tales ciegos ¿lo son de los ojos de la cara o serán más bien ciegos de amor?

El dilema, apropiadamente cornutus, no necesita de respuesta para situar al personaje en un terreno de neto cariz erótico. Va muy acorde con una segunda serie de insinuaciones que culmina en aquella advertencia apicarada contra las caídas de espaldas, siempre citada por todos los críticos con gustoso escándalo. Porque salidas muy similares nos enteran, por ejemplo, de que, si bien su marido no la ama gran cosa, también ella, a su vez, no ha dejado de añorar a cierto galán con quien no la dejaron casarse. La serie hasta ahora comentada, con su oquedad sospechosa, podría ser calificada de "unas razones que ni atan ni desatan, y no significando nada, pretende el que las dize, con su disimulación, engañar a los que están oyendo", que es como define Covarrubias lo que en su tiempo llamaban bernardinas ${ }^{7}$. Son éstas un juego entre lo pleno y lo vacío, destinado a desconcertar o confundir al oyente, dejándolo indefenso para los fines genéricamente dolosos que procuran encubrir aquellas "palabras vanas" y "kasi mentiras", en equivalencia a "burlas, chanzas y adulaciones", según el testimonio de Gonzalo Correas. Preciosa domina a la perfección dicho recurso técnico, pero con estas salidas sobre

guerra de Granada don Fernando de Válor, figura popularizada por los romances de Ginés Pérez de Hita. Pero es conjetura más que improbable, por cuanto su Segunda parte de las guerras civiles de Granada no se publicó hasta 1619. "El rey de las Alpujarras" no figura aquí sino en cuanto mero signo de "personaje fabuloso'.

7 Gonzalo Sobejano, "Bernardinas en textos literarios del Siglo de Oro", HRM, 2, 247-259. También el excelente estudio de Monique Joly, La bourle st son interpétation. Recherches sur le passage de la facétie au roman (Espagne, $x v i^{e}-x \pi i i^{e}$ siècles), Université de Lille, Lille, 1982, pp. 138-142. 
los ciegos y las caídas de espaldas cultiva también, de un modo claro, la $p u l l a^{8}$, en cuanto gran forma alternativa de la burla verbal en la época. Basada en una comicidad más agresiva e inmediata, calco en principio del lenguaje de carreteros y gentes del camino, consiste la pulla en un acercamiento calculado a la expresión de insulto desvergonzado o rafez. Y como se verá, la gitanilla se muestra temible al envolver a toda la casa del teniente en una espesa red de pullas según el modelo más clásico.

Frente a las graciosas, revueltas perogrulladas de sus bernardinas, las pullas de la buenaventura se suceden sobre todo en desarrollo lineal de un concreto periplo somático, abarcador de ambos cónyuges y contagiado de claros sentidos obscenos. Con harta intención está ausente de allí la cara, parte más noble del cuerpo y espejo del alma, como si quisiera decir que estos personajes no son más que una baja y elemental biología. Comenzando por las manos, el poema rinde su grotesco viaje en las frágiles espaldas de la señora, tras haber dado vista a sus antípodas y a cierto sol $l^{9}$ no tan eufemísticos. Pulla antológica es la que denuncia los culpables jugueteos del teniente, demasiado aficionado como se sabe a "arrimar la vara". La frase se halla claramente calcada sobre otras como doblar o torcer la vara, muy usadas en la época a modo de perífrasis eufemísticas para 'injusticia, cohecho', aludiendo a vara como insignia de autoridad civil. Así el mismo Cervantes en Pedro de Urdemalas: “De vos, Crespo, será tan bien regida / Que no la doble dádiua ni ruego"' (Jornada primera). Y en Lope: ( $E l$ niño inocente de la Guardia, acto I):

Aquí, en Francia, son hombres de buen pecho los ministros, notarios y escribanos; no hay hombre descompuesto o que presuma torcer la vara, ni afrentar la pluma.

Sólo que la vara en este caso no se tuerce ni dobla, sino que se

${ }^{8}$ J. P. Wickersham Crawford, “Echarse pullas: A Popular Form of Tcnzone", $R R, 6$ (1915), 150-164; Joly, op. cit., 246-267. "Por su parte, la pulla tiene una intención punzante, burlescamente ofensiva, de que la bernardina carece por lo general. El que echa pullas, más que engañar quiere humillar, avergonzar, vejar"; por lo mismo son "más abundantes en novelas picarescas, comedias de enredo y entremeses que en obras literarias" (SOBEJANO, op. cit., pp. 250 y 256 ).

9 "Entre los rayos de tu sol (in cunno)" (Pierre Alzieu, Yvan Lissorgues y ROBERT JAmMes, Floresta de poesías eróticas del Siglo de Oro, France-Ibérie Recherche, Toulouse, 1975, 88, 16). Sol, símbolo de "generative heat, fertility", en AD DE VRIES, Dictionary of Symbols and Imagery, North Holland, AmsterdamLondon, 1974. 
arrima ${ }^{10}$ en toda su entereza y en un obvio sentido sexual, dando así causa justificada a los celos de la tenienta. La dicha vara se halla, de nuevo, determinada por su etimología, que no ofrecía ninguna duda para Covarrubias: Latine virga, auasi verga, a virga. Su verdadero sentido es, por supuesto, el de verga 'pene' no poco frecuente en la época ${ }^{11}$. Semejante pulla, situada al comienzo del poema y dirigida al esposo, equilibra a su final con la no menos arriscada del lunar cercano a los "oscuros valles"' 12 de su mujer. Antipodas, con su implícito recurso a la idea de redondez, se orienta hacia las mismas fronteras anatómicas. Francesillo de Zúñiga había hablado de las amplias antífonas ${ }^{13}$ de la obesa doña Germana de Foix.

Se agrupa otra serie no menos intencionada en torno a una idea extraña e inesperadamente eclesiástica. Pues resulta que la doña Clara tiene ya mucho andado, con "más de cuatrocientas rayas", para un incongruo destino de abadesa, que no puede hallarse más alejado de sus inclinaciones, no poco galantes como ya se ha visto. Lo mismo cabe decir de la hija aún no nacida, cuya belleza "rubia y blanca" no parecería tampoco anticipar una vocación de religiosa y menos aún el cargo de prelada, si no es ya a título de herencia biológica de su madre. Se reserva también para ésta el orgullo de ver al hijo canónigo, si bien podrá serlo en cualquier Iglesia menos en la de Toledo.

Bajo un momentáneo aire de respetabilidad no dejaban de manifestarse aquí intenciones tan definidas como injuriosas. La asimilación monja-ramera se hallaba muy viva en la lengua popular del momento. En Juan de Luna (1620) leemos: "Al cabo de po-

${ }^{10}$ Arrimarse, "llevar o practicar el queridaje o amancebamiento; relaciones amorosas no legalizadas", según José Luis Alonso Hernández, Léxico del marginalismo del Siglo de Oro, Universidad, Salamanca, 1976. Véanse también los textos correspondientes a arrimada y a arrimadillas en ALzIEU, Lissorgues y JAMMES, op. cit.

11 "Se llama también el miembro de la generación de los animales mayores"' (Dicc. Aut.). Ejemplos en Alonso Hernández, op. cit. Para su lexicografía diacrónica, Camilo José Cela, Diccionario secreto, Alianza-Alfaguara, Madrid, 1971, t. 2. En 1588 el mismo Cervantes dio un soneto laudatorio para el libro del doctor Francisco Díaz titulado Tratado de todas las enfermedades de los riñones, vexiga y carnosidades de la verga y urina.

12 "Y $Y$ aunque sintió haber entrado / el cura en el valle ajeno / nunca me dijo / malo ni bueno", Alzieu, Lissorgues y Jammes, op. cit., p. 174.

13 "Y una noche estando con ella en la cama, tembló la tierra (otros dicen que las antífonas desta Reina)", Crónica burlesca del emperador Carlos $V$, ed. Diana Pamp de Avalle-Arce, Crítica, Barcelona, 1981, p. 140. Es aquí aplicable la nota de Alzieu, Lissorgues y Jammes, op. cit., 91, 15. 
cos días vi a la doncellica religiosa en la casa de poco trigo", 14 Monja de la $P .{ }^{15}$ tenía un significado inconfundible y Quevedo se refirió, creador como siempre, a "las hermanitas del pecar" ${ }^{16}$, mientras que se llamaba ermita a la 'botica de la ramera'17. Abadesa significaba, entonces como ahora, 'puta vieja' y, por extensión, 'alcahueta'18. Así en la jornada primera de la Tinelaria (1517) de Torres Naharro:

\section{BAR. ................. \\ Buscam'ora por allá una dessas putas viejas \\ BAR. ¿Abadessa? \\ Esc. Y aunque sea prioressa.}

Preciosa se refiere, naturalmente, a un monjío de esta especie non sancta, pues reconoce en la señora cualidades rameriles en un grado de verdadera preeminencia abacial. Si llega a tener una hija, tampoco le es difícil vaticinar que ésta habrá de seguir los mismos ilustres pasos, como astilla que será de tal palo. Las que podemos llamar serie somática y serie eclesiástica o monjil termi-. nan por coincidir de esta forma en una misma imagen fornicante de intenciones en alto grado vejatorias.

Hay un cambio de clave en lo relativo al hijo canónigo, porque la rotunda afirmación de que no lo será de Toledo significa, simplemente, que no podrá ofrecer las credenciales de limpieza de sangre que el famoso Estatuto del arzobispo Silíceo (1547) ha vuelto indispensable para el goce de cualquier beneficio en el primer cabildo del reino ${ }^{19}$. La gitanilla no está dispuesta a quedarse con nada dentro del cuerpo y recurre a pullas, si cabe, de aún

${ }^{14}$ La segunda parte de la vida de Lazarillo de Tormes, ed. E. R. Sims, University of Texas, Austin, 1928, p. 65.

15 Alonso Hernández, op. cit.

16 "Tasa de las hermanitas del pecar hecha por el fiel de las putas", Obras completas en prosa, ed. L. Astrana Marín, Aguilar, Madrid, 1945, p. 87.

${ }^{17}$ Alonso Hernández, op. cit.

${ }^{18}$ El Dicc. hist. aduce textos que se extienden de 1517 a 1942 , correspondientes para la etapa contemporánea a varios repertorios hispanoamericanos y a escritores como Pío Baroja. "Las señoras abadesas" en contexto también obsceno, Jack Weiner, El Cancionero de Sebastián de Horozco, Herbert Lang, Berna, 1975, p. 207. "Pardon, je voulais dire de monastère" (MAUPAsSANT, La Maison Tellier).

${ }^{19}$ Amplia discusión y datos acerca del mismo en Albert A. Sicroff, Les statuts de 'pureté de sang' en Espagne du xv $v^{\ell}$ au xvii ${ }^{\ell}$, siécle, Didier, Paris, 1960; "Los estatutos de limpieza de sangre", en Antonio Domínguez Ortiz, Los judeoconversos en España y América, Istmo, Madrid, 1971, pp. 79-104. 
más grueso calibre. Por si no hubiera dicho bastante de la tenienta, Preciosa la tacha, además, de ser ex illis, llamándola así, en su misma cara, puta judía. Hay cambio, pues, de clave, pero siempre sobre un mismo carril de infamia que consolida las dos obscenidades de sexo y de linaje, conforme a un claro paradigma de época ${ }^{20}$. La buenaventura se ha vuelto una denuncia integral, burla deshumanizadora que arranca, una tras otra, las hojas de parra y sucesivamente expone a vista de todos las vergüen'zas corporales del teniente y de su esposa. Tras ello, un verdadero ensañamiento sacará también a relucir las faltas de conducta privada y hasta las lacras de la misma sangre.

Tan agresivo proceder de la gitanilla responde, como veremos, a causas justificadas y no es caprichoso ni gratuito. Más aún, el poema queda integrado a la estructura narrativa, en cuanto culmen del episodio del teniente, por los segmentos transicionales que suponen la acogida y el adiós de Preciosa en casa de éste. Es allí donde surge el conflicto, cuya lógica correlativa provoca el recurso a un lenguaje ya militante, pero ceñido por el momento a un plano de virtualidad ${ }^{21}$ semántica. Se imponen allí las que Mijail Bajtín llama, al tratar de las metáforas somáticas del lenguaje carnavalesco, "alogical spheres of unpublicized speech" ${ }^{22}$, bajo

${ }^{20}$ La asimilación de ambos deshonores queda perfectamente ilustrada por una anécdota que trae fray JUAN DE PINEDA en sus Diálogos familiares de la agricultura cristiana: "Yo sé de uno de mi facultad [médico], que, llevándole a vistas con la criada de un caballero, después de parlar un rato en buena conversación, ella le dijo en secreto que no le quería engañar en cosa tan grave y que supiese había errado, aunque ninguno lo sabía, por tanto que viese lo que le compiía; y él se lo agradeció mucho y la tuvo por muy discreta, y la dijo que que él quería descubrirla otra falta en pago de la suya, que era un poco judío, y que no quería que ella lo supiese de boca ajena; y ambos se casaron y vivieron muy contentos" (ed. J. Meseguer Fernández, Adas, Madrid, 1964, t. 4, p. 28).

${ }^{21}$ Entra aquí en juego la teoría sobre el virtuema o sema variable y no denotativo formulada por B. PotTIER, Présentation de la linguistique. Fondements d'une théorie, Klincksieck, Paris, 1967, p. 27. Como observa Pierre Giraud, “il n'est guère de verbe actif, et plus particulièrement de verbe transitif, ni de nom d'agent, d'instrument ou de patient, qui ne contienne une image sexuelle en puissance, prête à se concrétiser au moindre clin d'oeil", Semiologie de la sexualité, Essai de glosso-analyse, Parot, Paris, 1978, p. 109. Véase también "L'écriture-calembour" en su aplicación a la lengua del erotismo, en C. DElacampagne, "L'écriture en folie", Poétique, 1974, núm. 18, 160-175. Sobre la presencia en la obra de expresiones de doble sentido, desconcertantes incluso para los mismos personajes, "Personenhandlung und Geschehen in Cervantes' Gitanilla", RF, 51 (1937), pp. 153 y 160.

22 "Ail these alogical spheres of unpublicized speech are manifested in 
las cuales la palabra más usual e inocente desarrolla donde menos se espera un filo agresivo, adaptándose a semas insultantes y obscenos diestramente manipulados. Por supuesto, se halla de por medio el poder destructor de la imagen eufemística, origen de inesperadas pero no desconocidas polisemias que tocan ya en las mismas fronteras de la lengua como instrumento de comunicación. El resultado, válido para todo el episodio, son dos textos fundidos en uno que sólo revela su plenitud expresiva a través de una "lectura estereoscópica"'23 a la vista de dichas virtualidades. Es decir, de lo que hasta ahora ha rehusado hacer la crítica, pero divertía de lo lindo al lector contemporáneo. Y como opinaba don Alberto Lista, "todo el que hace reír tiene razón"”24.

La buenaventura acota después un espacio donde irrumpe, al fin, una libertad expresiva incompatible, al parecer, con la deferencia impuesta a Preciosa por el inconmensurable desnivel social de las personas a que ha de entretener. Lo que ocurre es que la gitanilla arde en su fuero interno desde el instante en que se da cuenta de que no ha de sacar de aquella casa más que hueros piropos a sus gracias naturales. Es claro que se están riendo de ella cuando le dicen no disponer de moneda de oro, plata ni cobre con que ni siquiera santiguar la quiromancia. Bajo apariencia inocente, la ofensiva se entabla en torno al menguado ersaiz supuesto por el dedal de plata que ofrece una de las doncellas.

modern times only when the serious goals of language have been dropped, when men are placed in conditions of extreme familiarity and engage in an aimless and uncontrolled verbal game, letting their imagination run from serious lines of thougth" (Rabelais and his World, M.I.T. Press, Cambridge, 1968, pp. 421-422). "In these unpublicized spheres of speech all the dividing lines between objects and phenomena are drawn quite differently than in the prevailing picture of the world" (ibid., p. 421). No es preciso encarecer la confirmada destreza mostrada por Cervantes en tal terreno (entremés de El viejo celoso, etc.). Véase también Donald McGrady, "The 'sospiros' of Sancho's Donkey", $M L N, 88$ (1973), 335-337 y el estudio del mismo "Notas sobre el enigma erótico con especial referencia a los Cuarenta enigmas en lengua española", Criticón, 1984, núm. 27, 71-108.

${ }^{23}$ Cllaude Allaigre y René Cotrait, " "La escribana fisgada": estratos de significación en un pasaje de La picara Justina", HNS, p. 47. Aunque en modo alguno sea posible considerar la buenaventura de Preciosa como imitación de La picara Justina, sí es cierto que no deja de ofrecer aquélla un fuerte sabor de época nada indiferente a las técnicas allí masivamente desplegadas por López de Úbeda. La polémica cercanía de ambos autores fue puntualizada en su día por Marcel Bataillon, "Urganda entre Don Quijote y La picara Justina", en Picaros y picaresca, Taurus, Madrid, 1969, pp. 53-90.

24 "Nueva edición de las obras festivas en prosa y verso de D. Francisco de Quevedo y Villegas", Ensayos literarios, Sevilla, 1844, p. 152. 

de plata?

—Niña, ¿hará algo al caso que se haga la cruz con un dedal

-Antes - respondió Preciosa- se hacen las cruces mejores del mundo con dedales de plata, como sean muchos.

Uno tengo yo - replicó la doncella-: si éste basta, hele aquí, con condición que también se me ha de decir a mí la buenaventura.

Lo terrible en dicho texto es la ambigüedad que contagia la semántica de dedal. No es de olvidar que el campo de la costura, hilado, etc., ha estado desde siempre míticamente unido con la idea de la mujer como sujeto erótico ${ }^{25}$, de donde viene, por ejemplo, la chanson de toile en la tradición medieval francesa. Y mucho más cercano el caso de Celestina, bajo cuyo primer confesable oficio de labrandera "muchas mozas de estas sirvientes entraban en su casa a labrarse y a labrar camisas y gorgueras y otras muchas cosas" (auto I). Pero como derivado, a la vez que imagen complementaria, de dedo 'pene', dedal se usaba frecuentemente con el sentido de cunnus $^{26}$. Entre muchas ilustraciones posibles, se impone citar aquí la muy gallarda de Góngora en su romance de 1585 "Ahora que estoy despacio":

Comadres me visitaban

que el pueblo tenía muchas;

ellas me llaman compadre

y taita sus criaturas.

Lavábanme ellas la ropa,

y en las obras de costura

ellas ponían el dedal

y yo ponía la aguja.

25 "There is a mystic connection between female initiations, spinning and sexuality. Even in developed societies, girls enjoy certain prenuptial freedom, and their meetings with boys take place in the houses where they gather to spin" (Mircea Eliade, "Spinning, Weaving, and Sexuality", en Myths, Rites, Symbols, Harper Books, New York, 1975, t. 2, p. 415). Sobre el hilar carnavalesco véase Agustín Redondo, "Tradición carnavalesca y creación literaria. Del personaje Sancho Panza al episodio de la ínsula Barataria en el Quijote", $B H i, 80$ (1978), p. 63; y acerca de la chanson de toile, Pierre Jonin, "Les types féminins dans les Chansons de Toile", Ro, 91 (1970), 433-466.

${ }^{26}$ Así en el equívoco acertijo $A$ un dedal de oro. "Es redondo, y de un metal / tan dulce para las damas / que dejan de ser doncellas / por él, y dentro de un horado / tiene, y de fuera mil mellas. / Por éste un miembro humanal / se mete, y tan bien alcanza / que no le hiere la lanza / de un ojo, ni le hace mal" (Alzieu, Lissorgues y Jammes, op. cit., p. 302). Para "dedo" mentula, véase ibid., 76 y 36; sobre digitus y manus, J. N. Adams, The Latin Sexual Vocabulary, Johns Hopkins University Press, Baltimore, 1982, p. 209. 
No menos también el diálogo en lengua española "muy claríssima"' de La Lozana andaluza (Mamotreto segundo):

TíA. ... que aquel mercader que vino aquí ayer me dijo que, cuando torne, que va a Cáliz, me dará remedio para que vos seáis casada y honrada, más querría él que supiéredes labrar.

Lozana. Señora tía, yo aquí traigo el alfiletero, mas ni tengo aguja ni alfiler, que dedal no faltaría para apretar.

Hablar, en tales contextos de un dedal de plata es modo de encarecerlo como objeto de calidad y altamente deseable. Pero dicha mención del precioso metal establece, además, un puente de asimilación con las "manos de plata" de su señora la tenienta y los semas, como de costumbre escabrosos, que en aquéllas van implícitas. Si la plata se dice ausente de las faltriqueras, no deja, en cambio, de hallarse al parecer bien escondida en las mismas personas.

Hay, pues, su poco o su mucho de desvergüenza en aquel "uno tengo yo", así como en la pregunta, no tan doncellil, sobre si puede "hacerse la cruz" con un "dedal de plata". Porque, en este plano del sobreentendido eufemístico, cruz asumía también más de un significado obsceno, entre ellos los de 'postura sexual' y 'genital femenino'27, además de 'ingle' y del valor de cruzar como 'procreación animal'. Toda esta picardía era bien conocida del Arcipreste de Hita, como se ve en su zéjel de Cruz cruzada, y no menos también por Preciosa al garantizar lo que cabe muy bien hacer o no hacer cuando se dispone de un "dedal de plata". Y el mismo juego de pulla virtual en torno a la dilogía de dedal persiste, reanudado, en el momento de la despedida, cuando la dueña de éste reclama su devolución y obtiene condigna respuesta:

- Señora doncella - respondió Preciosa-, haga cuenta que se la he dicho, y provéase de otro dedal, o no haga vainillas hasta el viernes, que yo volveré y le diré más venturas y aventuras que las que tiene un libro de caballerías.

El contexto hasta ahora examinado vuelve asimismo malicioso este consejo sobre abstenerse de hacer precisamente vainillas,

${ }^{27}$ Claude Allaigre y René Cotrait, "Foissonnement du sens et niveaux de lecture dans la 'trova cazurra' de Juan Ruiz", $R L R, 80$ (1973), pp. 69 y 71 . Y más claramente aún en el intercambio obsceno acerca de cruz entre caballero y dama en el Valladolid de hacia 1605, cuando ella responde: "Así debe ser, que la mía está en jardín y la vuestra en muladar" (TOMÉ PiNHEIRO DA VeIGA, Fastiginia o fastos geniales, trad. N. Alonso Cortés, Valladolid, 1916 , p. 82). 
al menos por unos cuantos días. Con mucho donde elegir dentro de la amplia terminología de estas labores ${ }^{28}$, se recurre a un diminutivo de vaina. De nuevo, una lexia inserta en la serie del erotismo somático por la obvia sugestión etimológica a vagina. Su sentido no es, pues, sino un escepticismo implícito acerca de la oficial y pregonada "doncella" del dedal de plata, así como de todo su sospechoso hacer ${ }^{29}$. El ingenio de Preciosa sabe hacer callar, implacable, a todo adversario.

Es de notar cómo ambas zonas de asumida virtualidad expresiva han sido calculadas para servir de prólogo y epílogo al agresivo discurso de la buenaventura. Sin dejar de constituir un diálogo apropiado a la básica situación de recompensa negada, el lenguaje penetra en un terreno definido por la complicidad en torno a efectos cómicos de un erotismo crudamente somático. La hábil preparación en torno a dedal, lexia legada conceptualmente al valor sexualizado de la mano, conduce sin transición brusca al "Hermosita, hermosita, / la de las manos de plata'. Sin todo este previo discurrir sólo cabría ver en tales palabras una simple fórmula de cumplimiento a las blancas manos de la dama. Pero dentro de un contexto de tal naturaleza, el lector volverá sobre sus propios pasos para preguntarse si aquello de manos de plata no ha de esconder también su gota de ponzoña. Porque el sentido habitual de dicho elogio es, a su vez, encarecedor de una gran destreza o habilidad aplicada a exigentes o menudas tareas, como ilustra el nom de guerre de "Manitas de plata", asumido en nuestros días por un famoso guitarrista o tocaor flamenco ${ }^{30}$. Pero después de sa-

28 Explicada en ISABel Turmo, Bordados y bordadores sevillanos (siglos xvi a xviii), Laboratorio de Arte, Sevilla, 1955.

${ }^{29}$ Abundantes ejemplos de "hacer" (futuere, concumbere, etc.) en Alzieu, LISSORGUES Y JAMMES, op. cit

${ }^{30}$ De nombre Ricardo Ballado. De entre su discografía, Vanguard SD 79203. Las fórmulas adulatorias aparecen, por lo demás, como características de estas situaciones. La Gitana de la Eufemia de LoPe DE RUEDA: "Dioz te guarde, zeñora honrada, Dioz te guarde, y una limoznica, cara de oro, cara de siempre novia, daca; que Dioz te haga prosperada y te dé lo que desseas, buena cara, buena cara!"' (Teatro, ed. J. Moreno Villa, Espasa-Calpe, Madrid, 1924, p. 82). La Lucinda de El arenal de Sevilla se dirige a sus clientes llamándolos "cara de rosa", "cara de pascua", "esa generosa mano", "mano de caballero" en el caso de unos capitanes, y "cara buena, cara hermosa" en el de una dama (su rival). Un caballero que se hace pasar por gitano pide allí entrada, suplicante, con un "ábreme, cara de plata". Tales expresiones debían considerarse como clichés del habla gitana, pues los personajes recurren a ellas a modo de máscara. La misma Lucinda confiesa que trae "estudiado el parlamento" (acto segundo) para fingirse gitana. Un cumplimiento acerca 
ber lo que ya se sabe acerca de la tenienta doña Clara, es válida cualquier perplejidad acerca de la clase de labor o instrumentos en que Preciosa desea adjudicarle tan alta distinción.

¿A qué apuntan estas páginas? La presentación del personaje dejó ya en claro que Preciosa " con todo esto era algo desenvuelta; pero no de modo que descubriese algún género de deshonestidad". Lo que se entiende por tal "desenvoltura" inculpable de la gitanilla va a quedar muy pronto aclarado por su rápida respuesta a la impertinencia de cierto "modorro" de la corte:

Otro más humano, más basto y más modorro, viéndola andar tan ligera en el baile, le dijo: “ ¡A ello, hija, a ello! ¡Andad, amores, y pisad el polvillo atán menudito!" Y ella respondió, sin dejar el baile: "Y pisárelo yo atán menudó!"

Los anotadores explican aquí, puntuales, la alu sión al popularísinıo baile del polvico, pero lo que ninguno añade es la conocida acepción de polvo, 'coito, fornicio'. Podrá parecernos mucho atrevimiento para una jovencita, pero el bon mot de Preciosa no responde sino a una moda del ingenio de la época y a lo que sabemos se esperaba de toda dama experta en usos de corte ${ }^{31}$. Por lo demás, la misma gitanilla va a dejar en claro poco después "que llega mi honestidad a mi desenvoltura" 32 .

De este modo la quiromancia de Preciosa va mucho más allá de acreditar la ya establecida "desenvoltura" de la muchacha. El poema cifra una situación novelística de hondo significado y éste se halla perfectamente servido por un ejemplo antológico con-

de la mano era también formulaico en estas prácticas de quiromancia. Así en la Farsa das ciganas de Gil VICENTE: "Qué mano, qué siño, qué flúrez!", "Dame acá, dulce serena, / esa mano cristalina", "O brancas manos de Izeu" (Obras, pp. 646 y 647).

${ }^{31}$ Como observa Alan S. Trueblood, "live conversation was already very much an art in its own right, one inherited by the Spaniards from Renaissance Italy", en cuanto una aplicación práctica de la literatura del ingenio: "The live conversations recorded in a work like the Fastiginia of Pinheiro da Veiga prove how agile and daring actual talk could be" (Experience and Artistic Expression in Lope de Vega. The Making of La Dorotea, Harvard University Press, Cambridge, 1974, p. 386). La respuesta de Preciosa no se halla, en efecto, muy lejos del tono de la dada al discreto portugués (amigo personal de Cervantes) por unas damitas vallisoletanas que comían cerezas (TOMÉ PINHEIRo DA VEIGA, op. cit., p. 66).

32 Esta "desenvoltura" de Preciosa es vista como epidesarrollo de un concepto escolástico de castidad fundado en temperantia por J. L. WOODWARD, " $\mathrm{La}$ gitanilla", CICer, t. 1, p. 448. 
forme a la modalidad bufonesca de la literatura del "loco". Cervantes no deja de seguir también aquí un rumbo prescrito por el humanismo cristiano, gran defensor del concepto paulino de la locura sabia, elevado a su máxima expresión por la Moria erasmiana ${ }^{33}$, y dentro del cual habría de escribirse el Quijote mismo. Sondeaba además, en otro sentido, la plena responsabilidad de comprender, en discrepancia con sus tiempos, la realidad social del gitano ${ }^{34}$, vista en último término como un problema de dignidad humana.

Todo queda perfectamente cifrado en aquel divertido poema. La buenaventura concentra y resume sin vacilación la enemiga profesada por la gitanilla a cuanto se relaciona con el teniente y su "estéril" casa de la corte. Determina ésta un ámbito narrativo marcado de primera intención por un aire lujurioso torpemente material, donde todos viven una envilecida hipocresía y nada es como aparenta, desde la vida privada de los amos hasta el "dedal" de la supuesta doncella. Cervantes no ha podido concebir

${ }^{33}$ El carácter bufonesco de la Moria erasmiana ha sido objeto de intenso estudio a partir del de Barbara Swain, Fools and Folly During the Middle Ages and the Renaissance, Columbia University Press, New York, 1932, pp. 135-156. Hitos de interés en la bibliografía posterior, Walter KaISer, Praisers of Folly. Erasmus. Rabelais. Shakespeare, Harvard University Press, Cambridge, 1963; y Donald Gwyn Watson, "Erasmus' 'Praise of Folly' and the Spirit of Carnival", $R Q, 32$ (1979), 333-353. Véase también "Le morosophe ou fol-sage", en Maurice Lever, Le sceptre et la marotte, Fayard, Paris, 1983, cap. 6. Para el caso particular de España, MARTINe Bigeard, La folie et les fous littéraires en Espagne 1500-1650, Paris, 1972, pp. 8, 125 y 134-135.

${ }^{34}$ Como pone de relieve Juan Bautista Avalle-Arce, "escribir una novela poblada por tipos literarios extrarradiados por las letras de la época, y que actuaban como definitorios de la obra a leer desde el propio título, todo esto constituía audacia y seguridad creativas"' (CERvantes, Novelas ejemplares, Castalia, Madrid, 1982, t. 1, p. 21). El compromiso cervantino con una objetividad de hecho favorable al grupo gitano es igualmente básica para los renovadores estudios de Marie LafrRanque, "Encuentro y coexistencia de dos sociedades en el Siglo de Oro. La gitanilla de Miguel de Cervantes", CH(5), 549-561, y de IsAÍAS LeRNER, "Marginalidad en las Novelas ejemplares. I La gitanilla", Lexis, 4 (1980), 47-59. Para la tradición del gitano en la escena y el caso particular de Pedro de Urdemalas, Jean Canavaggio, Cervantes dramaturge, P. U. F., Paris, 1977, p. 123. Sobre el caso del gitano en el mapa de la marginación española de la época, cf. JEAN VILAR, "Le picarisme espagnol: de l'interférence des marginalités à leur sublimation esthétique", Les marginaux et les exclus dans l'histoire, Union Générale d'Éditions, Paris, 1978, pp. 29-77; la característica "superstition divinatrice", p. 42. Para la situación del gitano de la época, las breves pero indispensables páginas de Antonio Domínguez Or. TIZ, "Documentos sobre los gitanos españoles en el siglo XVII", Homenaje a Julio Caro Baroja, Centro de Investigaciones Sociológicas, Madrid, 1978, 319-326. 
el episodio sino apuntando a blancos muy específicos, y es aquí donde encaja, oportuna, la reciente interpretación de A. G. Forcione, que ve en aquel cuadro la condena de un matrimonio pervertido, justo al uso de la vida de corte y reverso del ideal puesto a prueba por los jóvenes enamorados. Pero aun si esto es básicamente aceptable, dista de justificar tanto la virulencia satírica de Preciosa como la modalidad expresiva por la cual ésta se rige. ¿Y de dónde conceder tanto relieve a un mero elemento de contraste? Porque la gitanilla no predica con su buenaventura contra esto ni aquello, sino que reacciona y sale airosa ante una situación $y$ ante un personaje que tiene delante. Para entenderlo es preciso volver a las circunstancias de la novela y partir de un dato fundamental y presente desde el primer momento:

Llegóse el tiniente, que era curioso, y escuchó un rato, y por no ir contra su gravedad, no escuchó el romance hasta la fin; y habiéndole parecido por todo extremo bien la gitanilla, mandó a un paje suyo dijese a la gitana vieja que al anochecer fuese a su casa con las gitanillas, que quería que las oyese doña Clara, su mujer.

Quiere decir esto que el teniente ha ejercido con ellas la prerrogativa de su cargo y que Preciosa no va a su casa sino obligada y en cumplimiento de una orden. La situación ofrece de por sí un carácter tenso, pues, como miembro de un grupo hostilizado, el gitano tiende a distanciarse físicamente de una autoridad que acostumbra a mirar sólo como amenaza y no se halla a gusto junto a sus detentadores. En este caso, el alto oficial de la corte encarna para las gitanas un poder destructor y absoluto, con el que hay que contemporizar por encima de todo, haciendo de tripas corazón y poniendo a mal tiempo buena cara. En nuestros días, Cervantes habría enviado a Preciosa a actuar en casa de un jefe de la guardia civil.

Este planteamiento de abusiva desigualdad, supone una coacción a prueba de buenas palabras y es clave de cuanto Preciosa hace y dice a lo largo de todo el episodio. La temperatura sube todavía muchos grados cuando aquélla se da cuenta de que, para colmo, habrá de salir de allí con las manos vacías. El diálogo que ocasiona la frustrada búsqueda de una solitaria moneda es, por supuesto, pura burla instantáneamente captada por la gitanilla. La idea de tanta penuria en torno al lucrativo y por lo común corrupto cargo es per se inaceptable para la muchacha, muy ajena en esto a la candidez con que los críticos modernos suelen darla 
por buena ${ }^{35}$. Por el contrario, reviste todo aquello el carácter de una broma premeditada, puesta de acuerdo tal vez con la esposa mediante el aviso de la visita de las gitanas. Tiende a confirmarlo así la perfecta continuidad con que el teniente prolonga después la comedia, declarándose también sin blanca. Su intención de siempre ha sido cumplir con Preciosa como con una mendiga, según traiciona al sugerir a doña Clara que le dé " alguna valoncica vuestra, o alguna cosita".

Ahora bien, Preciosa es lo que hoy llamaríamos una artista profesional, muy hecha, dentro de su humildad, a verse generosamente recompensada (como tanto remacha el texto) por su donaire, ingenio y belleza ${ }^{36}$. A falta de otras virtudes, la corte no es tacaña, al menos, con unas dotes privilegiadas para el canto

${ }^{35}$ Como el mismo ICAZA (op. cit., p. 112) con sus datos, que cree comparables, acerca de la absoluta pobreza que a veces caía sobre la misma casa real. Olvida mencionar, dentro de dicho cuadro, el contraste con la opulencia de favoritos y oficiales abiertamente dados al cohecho. Es claro que La gitanilla no censura al rey, sino a una administración corrupta y al mal ejemplo de la corte, entendiendo por tal la alta esfera madrileña. Por lo demás, es también de notar que la Farsa das ciganas de GiL VICENTE ilustra la misma situación de falta de generosidad por parte de las damas a quienes han dicho la buenaventura, y así la despedida de las gitanas Cassandra, "Señuraz, con benedicion / Os quedad, puez no dais nada" y Lucrecia, "No vi gente tan honrada / Dar tan poco galardón"' (Obras, p. 650).

${ }^{36}$ El detalle de la abundante recompensa económica de Preciosa sólo ha sido comentado por GÜNTERT, para quien constituye una extensión de la básica imagen narrativa Preciosa = joya = Poesía y por ello "nunca se exhibe en público sin cobrar, pero al mismo tiempo se distingue de su ambiente por conservar entera su pureza en medio de una vida libre, demasiado libre, como es la de los gitanos" (art. cit., p. 109). Sin necesidad de ir tan lejos, la ganancia de Preciosa en la corte se acredita como un rasgo realista, hábilmente puesto a contribución por la estructura narrativa. En cuanto a la vida ejemplarmente casta de Preciosa, es útil recordar que las abundantes quejas y legislación de la época no acusan nunca de liviandad a las gitanas. La fidelidad conyugal de éstas era una realidad observable hasta el punto de constituir un tópico particularmente molesto para Lope, que les encontraba aquel gran "defecto". Así los capitanes que miran a una guapa gitana en El arenal de Sevilla: Cast. “ ¿Bella mujer!”. Faj. "Hay de aquestas / algunas limpias y hermosas". Cast. "Sí, pero muy desdeñosas / y notablemente honestas, / que tienen extraña ley / con sus maridos" (acto segundo). No cabe decir, pues, que en este aspecto resulte Preciosa una criatura inmune a la influencia del medio ambiente, como mantiene Frank Pierce, "La gitanilla: A Tale of High Romance", BHS, 54 (1977), p. 284. La realidad en esto era, pues, totalmente opuesta a lo que creen Franz RAUHUT ("Consideraciones sociológicas sobre La gitanilla", ACerv, 3, 1953, p. 146) y más aún Joaquín CaSalduero, con su "nada de gitanismo, sino platonismo tridentino" (Sentido y forma de las "Novelas ejempla" res", Gredos, Madrid, 1969, p. 73). 
y la danza. La gitanilla aborrece, por eso, el tener que hacer su oficio contra su voluntad, divirtiendo a su natural enemigo y, para colmo, de balde. Sus jornadas por plazas y casas nobles de Madrid han de verse como un duro trabajo, ejercido con la mayor honradez personal y artística, en desempeño de una seria responsabilidad hacia los intereses de su aduar. Y en esta caracterización de la actividad "laboral" de Preciosa surge, de nuevo, un testimonio firme del exacto conocimiento cervantino de las estructuras sociales del grupo gitano. Las cosas apenas han cambiado y recientes estudios de campo insisten también en el prescrito carácter estable y cotidiano de la aportación económica de la mujer gitana, por contraste con la más voluminosa, pero aleatoria función de la actividad masculina ${ }^{37}$.

Sólo así se comprende lo que allí ocurre y la profunda ruindad de la conducta del teniente, que impone, abusivo, a las gitanas un servicio personal, como si ya tuvieran éstas que estarle agradecidas por el mero hecho de no enviarlas a la cárcel. Quiere decir que no estamos sino ante una faceta más de la honda preocupación de Cervantes y otros ingenios contemporáneos (Mateo Alemán, Suárez de Figueroa, etc.) por la obvia degradación de la justicia ${ }^{38}$, cuyos oficiales crecen en arrogancia a medida que se

37 : 'La mujer tiene como único estímulo positivo el ganar dinero, mientras que cualquier otra motivación tiene un carácter negativo, de presión. Como ya comentamos a su tiempo, en su propio sistema de valores y según los modelos tradicionales, la mujer está más estimulada a ganar dinero que el hombre, sea cual sea la forma" (Equipo Giems, Los gitanos al encuentro con la ciudad: del chalaneo al peonaje, Edicusa, Madrid, 1976, p. 178). La buenaventura y otras actividades adivinatorias, a la vez que exclusivamente femeninas, se estudian aquí bajo el epígrafe de Mendicidad y se caracterizan por su retribución a voluntad del cliente (p. 83). La consideración de estos hechos permite acotar, una vez más, el contraste entre Preciosa y la otra "gitanilla" Belica de Pedro de Urdemalas, la cual se niega a bailar si no es ante el rey y con miras a ser su concubina, para escándalo de su buena compañera Ynés. Se pone así de manifiesto que esta fría y calculadora Belica no es, en absoluto, gitana, sino un miembro al uso de la alta nobleza a que pertenece por su nacimiento: "Aunque tan sólo sospecha su ascendencia aristrocrática, revela el desprecio tradicional que esta clase social siente por el trabajo ordinario"' (STANisLAv Zimic, "El gran teatro del mundo y el gran mundo del teatro en Pedro de Urdemalas", Acta Neophilologica, 10, 1977, p. 78). Desacredita todo esto las interpretaciones de La gitanilla como otra Fuerza de la sangre, donde las virtudes de Preciosa se justificarían por el carácter inextinguible de su noble prosapia. Pero Cervantes no en vano se ha tomado el trabajo de aclarar que los padres de Costanza, nobles que sólo ven el lado socialmente ventajoso del matrimonio de ésta, distan mucho de ser como ella. Cervantes muestra aquí, una vez maś, su baja opinión de la aristocracia tomada como grupo social.

38 El blanco a que apunta Cervantes es tan obvio como para hacer excla- 
vuelven más corruptos. Preciosa considera al teniente por lo menos capaz, como casi todos, de venalidad, con su "coheche... y no haga usos nuevos", lo mismo que antes dijo también que su vara no se hallaba a prueba de ciertos "arrimos". La novela entera muestra el trato parcial y discriminatorio de que son objeto los gitanos, obligados incluso a depositar fianzas por el mero derecho a acampar en un término concejil ${ }^{39}$. La prisión de un supuesto gitano se realiza, como sabemos, con lujo de insultos y bofetadas por parte de justicias que no recatan su odio y el mismo desenlace de la obra ilustra a las claras que la justicia no es igual para todos ${ }^{40}$. No se olvide que don Quijote había aconsejado a Sancho un trato digno de los reos: "Al que has de castigar con obras no trates mal con palabras, pues le basta al desdichado la pena del suplicio, sin la añadidura de las malas razones"' (II, 42). Y hasta el más que rústico Juan Rana, candidato a la alcaldía de Daganzo, incluye entre sus promesas electorales:

Nunca deshonraría al miserable

Que ante mí le trajesen sus delitos;

Que suele lastimar una palabra

De un jüez arrojado, de afrentosa,

Mucho más que lastima su sentencia,

Aunque en ella se intime cruel castigo.

No es bien que el poder quite la crianza,

$\mathrm{Ni}$ que la sumisión de un delincuente

Haga al juez soberbio y arrogante.

Pero en el desenlace de La gitanilla se ha de ver todavía a un corregidor, padre de Preciosa, envilecerse como tal juez con esta clase de lenguaje, supuestamente bromista y sin duda harto bien ensayado:

mar a GonZÁLeZ de Amezúa: “¡Hacer usos nuevos llamaba Cervantes a administrar recta y austeramente la justicia! ¿Qué idea tendría él de la venalidad y corrupción de la de su tiempo!", op. cit., p. 28. Las claras intenciones de Cervantes acerca de este punto son bien resumidas por ISAÍAS LERNER, art. cit., pp. 52-53. Sobre la obsesión cervantina con la justicia, Francisco OLMOS GARCÍA, "El caballero cervantino, juez ejemplar", CSo, 114-123.

${ }^{39}$ Rafael Salillas señalaba el dato acerca de tales fianzas como totalmente único, fuera de su fidedigna documentación por Cervantes (citado por JuLIÁN APRÁIz, Estudio histórico-crítico sobre las "Novelas ejemplares" de Cervantes, Vitoria, 1901, p. 24).

40 Observación de Franco Mer egaldi, "Le Novelas ejemplares nello svolgimento della personalità di Cervantes", LM, 10 (1960), p. 344. 
- ¿Cómo está la buena pieza? ¡Que así tuviera yo atraillados cuantos gitanos hay en España, para acabar con ellos en un día, como Nerón quisiera con Roma, sin dar más de un golpe! Sabed, ladrón puntuoso, que yo soy Corregidor desta ciudad, y vengo a saber, de mí a vos, si es verdad que es vuestra esposa una gitanilla que viene con vosotros.

La buenaventura de Preciosa representa entonces una oportunidad liberadora, en cuanto terreno de excepción en que cobrarse las cuentas pendientes llamando a las cosas por sus nombres. La presentación ingeniosa salta por encima de la materia rafez, al mismo tiempo que la intensifica y legitima con el poder vivificador de la risa. Si todo esto suena hoy extraño y escandalizaba a la crítica positivista, no ocurría así con la conciencia literaria de la época, hondamente familiarizada con la figura del "loco" o bufón de corte y con su estética de paradoja ${ }^{41}$. Es preciso entender que el gitano compartía con el loco (y con el judío) una reconocida indignidad o anomia en cuanto ente de existencia marginada ${ }^{42}$, lo cual bastaba para hacer de él un bufón nato. Pero, además, dicho ser y no ser le ungía al mismo tiempo con el carácter numinoso de un contacto directo con lo sobrenatural, de donde también su compartir el don profético atribuido a los dementes $^{43}$, origen sin duda de la creencia popular puesta a con-

${ }^{41}$ Las categorías de ambigüedad, ambivalencia e ironía, reductibles al planteamiento lógico de la paradoja, resumen el legado del Renacimiento activo en toda la tradición moderna, según la tesis de Rosalie L. Colie en su brillante estudio Paradoxia Epidemica: The Renaissance Tradition of Paradox, Princeton University Press, Princeton, 1966; sobre el carácter paradójico de la literatura de la locura erasmista, véanse pp. 15 ss.

${ }^{42} \mathrm{La}$ afinidad funcional del "loco" respecto al judío y al gitano, por compartir con ellos una infamiae macula, con la consecuente marginación social, es puesta de relieve por ANTON C. ZIJDERVELD, Reality in a Looking-Glass: Rationality Through an Analysis of Traditional Folly, Routledge \& Kegan, BostonLondon, 1982, pp. 86, 113 y 115. Zijderveld, a su vez, confiesa su perplejidad al encontrar muy escasa evidencia histórica en confirmación de su análisis (p. 115). Al igual que todos los críticos estructuralistas de la literatura del "loco", no tiene la menor noticia del gran desarrollo de ésta en España ni del apoyo que en ella podrían encontrar sus mismas tesis. Es curioso cómo en El arenal de Sevilla cuando el protagonista y su criado han de disfrazarse de gitanos, comenta este último: "¿No te agradas / de verme en forma de loco?" (acto tercero).

${ }^{43}$ Sobre la idea, universalmente aceptada, del loco cual vehículo de inspiración divina véase ENID Welsford, The Fool. His Social and Literary History, Faber \& Faber, London, 1935, p. xi. La literatura medieval objetiva en Merlín la figura del loco profético (PENÉlope B. R. Doob, Nebuchadnezzar's Children: Conventions of Madness in Middle English Literature, New Haven, 1974, p. 
tribución en la costumbre de la buenaventura. Esta supuesta facultad adivinatoria transforma a Preciosa en mera voz del Hado y, deshumanizándola en cuanto instrumento o medium, la absuelve al mismo tiempo de responsabilidad en sus palabras. Reducida así a nada, puede asumir toda su humana plenitud y responder a la burla de que es objeto con otra aún más agresiva y cáustica, como si de repente hubieran cedido por milagro todas la barreras sociales. Tan cumplida pericia no ya en decir la buenaventura, sino en el ejercicio del arte bufonesco, se ve que forma parte, por lo tanto, de las "gitanerías" transmitidas por la gitana vieja. Preciosa se vuelve allí por partida doble una "loca", que al ejercer los privilegios de la locura lúcida conduce, como mandan los cánones, a un despliegue irreverente al servicio de la verdad moral, entendida como un absoluto incorruptible. Y desde luego, también a muchas carcajadas.

El loco de corte encarnaba entonces la noción del entretenimiento y pasatiempo aristocrático en su forma más pura y refinada $^{44}$. Sociológicamente, el bufón surgía de las filas indiferenciadas de los entertainers, en especial los profesionales, como Preciosa, del canto y del baile ${ }^{45}$. La entrada ocasional de la gitanilla

1550). El humanista aragonés JERÓNIMO DE MONDRAGóN, al hacer en 1599 un elogio del loco directamente inspirado en Erasmo, recordaba cómo "los turcos los respectan como a santos" (Censura de la locura humana y excelencias della, ed. A. Vilanova, Selecciones Bibliófilas, Barcelona, 1953, p. 151). La noción del carácter sacro de los enfermos mentales no se había desvanecido en la España de la época, como observa JuAN José López IBor, "Ideas de Santa Teresa sobre la melancolía", $R E, 22$ (1963), p. 439. En El principe melancólico (hacia 1588-1595) de Lope de Vega, un fingido loco dice al rey: "No puedes ver tú mi pecho / porque soy casí divino" (jornada segunda). En El halcón de Federico (entre 1601-1605) el loco Perote formula donosamente la profecía, rigurosamente cumplida, de que el protagonista cobrará a la dama con un halcón. Ei mismo origen se reconoce a la irresponsabilidad de la censura del loco: " $\mathrm{He}$ was not therefore expected to obey any code, and in this respect medieval toleranee gave the idiot considerable freedom to speak and act in ways for which others would have been severely punished"', Walter KaISER, Praisers of Folly. Erasmus. Rabelais. Shakespeare, p. 7.

${ }^{44} \mathrm{El}$ "loco", según el clásico libro de ENID WELSFORD, "has always been one of the great recreations of mankind and particularly of civilized mankind" (op. cit., p. xi). El bufón ejercía sobre todo a la hora de la comida de su señor y como escribe Jerónimo de MondraGón, "parece que los locos tienen de sí... cierta propiedad o virtud oculta para atraher i ganar las voluntades o las gentes, porque vemos que cada qual se deleita mucho con ellos, i de los príncipes son tan queridos i estimados. He visto io a príncipes, dexar secamente a hombres mui sabios, por sólo conversar con locos...", op. cit., p. 177.

45 Zijderveld, op. cit.; p. 5 . Sobre la presencia de la actividad musical en 
en dicho papel es, por tanto, espontánea y casi obligada como forma de acreditar su discreción y entereza mediante una prueba de fuego para sus dotes de ingenio y dominio de las últimas fronteras de su oficio. Tanto su actitud, profundamente adversaria bajo una apariencia de total sumisión, como su recurso a los temas del aspecto inferior del cuerpo ${ }^{46}$, no representan sino su destreza en el manejo de una gramática literaria bien aprendida. El máximo arte del bufón consistía, convencionalmente, en zaherir bajo formas externas de adulación cortesana y el oficio del truhán de corte se comparaba así ai de los perros por su habilidad para "lisonjear mordiendo"'47.

Preciosa no ha podido ir más allá en este arte, por excelencia cortesano, de insultar con la lisonja y su reverso, que es lo mismo, de lisonjear con el insulto. Para nosotros, su buenaventura cuenta hoy como prodigio de lenguaje al servicio de un concepto de género, problema técnico allí resuelto con la más elegante eficacia. No hay que olvidar que bernardina y pulla constituían recursos elementales de la comicidad bufonesca, pero que por lo común distan de dar tanto de sí, muy en contraste con los complejos casos de mestizaje y virtualización semántica ya analizados. La bernardina, en particular, ilustraba el habla inconexa de la locura, mientras que la pulla era considerada como una de las piedras angulares del mester truhanesco ${ }^{48}$. En la buenaventura de Preciosa, la primera es un elemento de distracción, que entrega a la víctima inerme ante el cuchillo de la lengua bufonesca. Ello es posible porque, a la vez, ésta misma se halla ab initio neutralizada y existe al precio de carecer de verdadera capacidad de injuriar o, dicho de otro modo, de existir en cualquier plano que no sea el de

la iconografía de la locura bufonesca, véase MAURizio Bonicatti, "La temática della follia in chiave moralistica: Sebastian Brant e Hieronymus Bosch", L'Umanesimo e la follia, Abete, Roma, 1971, p. 36.

46 "The Grotesque Image of the Body and its Sources", Mikhail BaKhTINE, op. cit., cap. 5. Sobre la obligada comicidad obscena del "loco" véase WILliam Willeford, The Fool and his Scepter. A Study in Clowns and Jesters and their Audiences, Northwestern Univcrsity Press, Evanston, 1969, p. 216.

${ }^{47} \mathrm{La}$ adulación esperada de los bufones era uno de los tópicos más usuales en la condena moral de éstos. Favorecía este concepto una clásica comparación del truhán con el perro, adulador, pero también capaz de morder 'murmurar, zaherir'. El León prodigioso de Cosme Gómez de Tejada los presenta así embutidos en pellejos caninos, pues "¿quál otro es el oficio de viles truhanes, sino lisonjear mordiendo?", JoLY, op. cit., p. 296.

${ }^{48} \mathrm{Ibid}_{\text {, }}$, p. 225. La dependencia de la bernardina respecto al disparate (fundamental para el lenguaje de la locura) no escapa a la atención de Sobejano, art. cit., p. 241. 
flatus vocis de un "loco", es decir, puro no ser desde un punto de vista de dinámica social ${ }^{49}$. Como en el caso de su cercano pariente Tomás Rodaja, sus pullas son "las del bufón cuya función de catarsis social era imprescindible al buen equilibrio de la organización estamental"'50.

El teniente y su esposa conocen perfectamente la clase de refriega que provocaron y en la que salen escaldados, justo como ocurre también a los duques en la segunda parte del Quijote. Porque el juego bufonesco llevaba en su centro el trueque de papeles, o sea la burla del burlador y la infamia del exaltado a manos del infame ${ }^{51}$, conducente a una inversión de polos entre príncipe y bufón. Esto es ni más ni menos lo que se entendía por una partida bien jugada y digna de incorporarse al jestbook particular de un "loco" de primera clase. Su desenlace era inapelable y los usos cortesanos exigían una aceptación que hoy llamaríamos "deportiva", pues nada había menos ortodoxo desde el punto de vista social que el dignificar a semejante adversario, reconociéndole la dimensión humana de responsable por sus hechos y dichos ${ }^{52}$. $L i$ benter enim suffertis insipientes: cum sitis ipsi sapientes, había predica-

${ }^{49}$ Lo mismo que rey y bufón son una coincidencia oppositorum, el valer todo o nada del segundo queda recogido por la función del joker de la baraja, según aguda observación de WILLEFORD, op. cit., p. 212. No menos interesante el caso de la comedia de Lope El valor de las mujeres (hacia 1615), donde una dama se hace pasar por bufón bajo el nombre de Valor: "Valor sin algún valor", la increpa en cierto momento otro personaje.

${ }^{50}$ JAcQues Joset, "Libertad y enajenación en El licenciado Vidriera", $C H(7), 2$, p. 617 . Sobre el bufón como elemento funcionalmente conservador en el seno de sistemas políticos de signo absolutista, véase ZIJDERveLD, op. cit. p. 120 .

$5 !$ Sobre la afinidad intercambiable de Rey, Sacerdote y Bufón en el seno de una sociedad autoritaria tradicional y sus funciones intercambiables, véase WELSFORD, op. cit., pp. 195 y 272. Para el ejemplo en esto señero de King Lear véanse Josephine W. Bennet, "The Storm Within: The Madness of Lear", SQ, 13 (1962), 135-155; Willeford, op. cit., pp. 208-225. Ayuda a comprender este aspecto de la radical agresividad del bufón el comentario de este último: "Thus the office of the jester fulfills some of the same functions as the ritualized rebellion in which political subjects express actual and possible resentments against authority. The fact that the rebellion encouraged implies that the social institutions and the persons in power are strong enought to tolerate it; thus it serves the interest of authority and of social cohesion" (ibid., p. 155).

${ }^{52}$ Es cierto que el bufón de corte pagaba a menudo con palizas y hasta con la vida, pero esta clase de venganzas se tomaban dentro del más absoluto anonimato. Nadie ha sabido jamás quién fue el Grande que mandó asesinar a don Francesillo de Zúñiga. El Narrenschiff (1494) de Sebastián Brant considera (n. 68) loco a todo el que toma en serio y se ofende por la burla del "loco". 
do San Pablo a los corintios (II, 11, 19). Y un personaje de nuestro Lope (El bobo del colegio, I):

El verte medio truhán apenas me determina para enojarme contigo.

Cervantes quiere que todo quede en su sitio y no deja de introducir su propio reclamo acerca de una lección magistral conforme a los cánones de la literatura bufonesca. La gitanilla ha demostrado, una vez más, ante aquellos seres sin rostro, "que hazer el loco a su tiempo es el maior saber de todos" 53 . En términos de época ha sido todo aquello un gran despliegue no de vulgaridad, sino de cortesanía. La desvergüenza del bufón no era en realidad suya, sino reflejo de quienes le pagaban y que, en este caso, ni siquiera eso hacían. Un "loco" creador o de legítimo ingenio era un hallazgo excepcional, ávidamente buscado para ofrecerlo, como joya viviente, a algún príncipe ${ }^{54}$, y es justo el caso de El licenciado Vidriera, cuya fama "llegando a noticia de un príncipe o señor que estaba en la Corte, quiso enviar por él, y encargóselo a un caballero amigo suyo que estaba en Salamanca que se lo enviase". La buenaventura de Preciosa es acogida, como corresponde a expertos catadores, con el tributo de la risa y una no velada admiración, porque lo han gozado a fondo con aquel lucimiento a pleno riesgo de su ingenio. Todos han entendido muy bien a la gitanilla, porque nadie es allí bobo y están hechos al trato y rituales del vivir palaciego. El teniente sabe reconocer el tesoro que tiene ante sí y reacciona acorde y previsible, entablando un diálogo perfectamente ilustrador por ambas partes. Nada desearía él tanto como la oportunidad de hacer valer en la corte las gracias de la gitanilla:

-Mucho sabes, Preciosa - dijo el tiniente-. Calla, que yo daré traza que sus Majestades te vean, porque eres pieza de reyes.

-Querránme para truhana - respondió Preciosa- y yo no lo

${ }^{53}$ Jerónimo dE MONDRAGÓN, op. cit., p. 179.

54 ZijDerveid aduce el ejemplo del famoso Thoni, bufón de Enrique II, Francisco I y Carlos IX, regalado a los reyes de Francia por su descubridor el duque de Orleans (op. cit., p. 104). Sobre intercambios de locos entre príncipes, véase LEVER, op. cit., p. 144. En la citada comedia de Lope El valor de las mujeres se presenta al descubridor del "loco" en acto de ofrecérselo al príncipe: "Os traje la mejor pieza / que hay en el húngaro reino, / en materia de locuras / y graciosos desconciertos, / sabe tañer y cantar, / sabe hacer famosos versos" (acto segundo). 
sabré ser, y todo irá perdido. Si me quisieren para discreta aún llevarme hían; pero en algunos palacios más medran los truhanes que los discretos. Yo me hallo bien con ser gitana y pobre, y corra la suerte por donde quisiere.

Pieza de reyes dice el Diccionario de autoridades, "se llama comúnmente el truhán o bufón, y assí al que es sabandija palaciega se dice que es pieza de rey'. Maestra en la grande y (hay que decir) noble tradición de la bufonería literaria renacentista, Preciosa la rechaza al mismo tiempo, acogiéndose al lado más estricto de una polémica moral de la época ${ }^{55}$. Todo esto tiene su importancia, porque la historia tradicional de la niña robada y su final anagnórisis asigna a ésta (según el relato bizantino de Apolonio de Tiro) un papel de juglaresa que en la versión de El Patrañuelo de Timoneda, obviamente conocida por Cervantes ${ }^{56}$, pasa a darla a conocer como La Truhanilla y probablemente sugirió la idea de presentar a Preciosa como centro de un episodio de esta clase. Pero esta otra gitanilla de nuevo cuño no quiere saber nada de príncipes ni de cortes, porque su vocación, como sabemos, no es de truhana (ni aun en el sentido de sabia predicadora de la risa), sino de enamorada y esposa. Contra su naturaleza hecha para la ternura, el bufón cortesano ha de ser en la vida real un sujeto cruel y despiadado ${ }^{57}$, porque el de truhán es un terrible oficio, que termina por deformar y encallecer el alma. Y aquí entra el factor decisivo de que la brillante actuación de Preciosa en casa del teniente no nazca más que secundum quid de ninguna libre voluntad,

${ }^{55} \mathrm{El}$ argumento de las inmerecidas recompensas y fortuna de los truhanes en la corte constituía un tema de obligada diatriba moral en la época (sin excluir al mismo Cervantes), conforme a la cara y cruz doctrinal del tema bufonesco. Planteamiento y abundantes datos en MoniQue Joly, "Fragments d'un discours mythique sur le bouffon', en Visages de la folie (1500-1650), eds. A. Redondo y A. Rochon, Université de Paris III, Sorbonne Neuvelle, 1981, 81-91.

${ }^{56}$ La relación de La gitanilla con el relato bizantino de Apolonio de Tiro fue advertida por Fitzmaurice-Kelly en su Historia de la literatura española (1898). Menéndez Pelayo (Orígenes de la novela, t. 2) se mostró favorable, con más acierto, al precedente supuesto por la patraña XI de El Patrañuelo (1567) de Juan de Timoneda, en cuanto reelaboración coetánea de dicha fábula medieval. Para una historia de la cuestión véase G. DE Amezúa, op. cit., t. 2, pp. 17-18. Sobre la amalgama en la obra de elementos bizantinos y picarescos, superados en una nueva fórmula, Avalle Arce, introd. a Novelas ejemplares, $\mathrm{t}$. 1, p. 24 .

${ }^{57}$ Como observa Zijderveld, los bufones de corte solían ser en la realidad "spiteful creatures", ligados al príncipe por una relación parasitaria, que los obligaba a actuar como "moral opportunists", op. cit., p. 112. 
sino que se perfile como única alternativa de reivindicar, al menos por un momento, su acorralada dignidad humana ante los orgullosos detentadores de todo el poder.

Tampoco el licenciado Vidriera quería para sí tal oficio, "que yo no soy bueno para palacio, porque tengo vergüenza y no sé lisonjear'. Pero a modo de hermano gemelo, y en lo que constituye una típica opción cervantina ${ }^{58}$, el ejercer de público bufón por las esquinas y plazas de la corte viene a ser para Rodaja la única manera de hacerse aceptar como sabio. El sentirse un vidrio a punto de quebrar en cada instante era sin duda un sentimiento típico y más común de lo que parece entre los españoles de la época. Curiosamente, el no menos truhanesco Antón de Montoro se había anticipado siglo y medio para titularse "esta triste de redoma / sin vasera" en su queja a don Alonso de Aguilar "cuando la destrucción de los conversos en Córdoba" ${ }_{59}$. Es el precio de una sociedad dividida entre puros e impuros y no se dan casualidades en todo esto, pues hoy sabemos del mecanismo enloquecedor con que la sociedad española hacía del mester bufonesco un lugar geométrico del judeoconverso ${ }^{60} \mathrm{y}$, por analogía, de todo desterrado interior, ilamárase gitano o algún talento crítico y disidente ( $¿$ no hay algo de gitanesco también en la vida de Cervantes?). En equivalencia de una imposible protesta, Preciosa se ha visto forzada a salir del difícil paso por un camino muy transitado, no menos pronta que otros a vivir del fardel de pullas que lleva a cuestas. En esencia ha procedido igual que Montoro o Villalobos y Cervantes maneja el caso como un ejemplo orgánico que equivale a un análisis acusador del sistema excluyeme. La discreta conducta de la gitanilla en casa del magistrado, así como su quiromancia de doña Clara, representan ya de este modo la

${ }^{58} \mathrm{M}$. JOLY habla por esto de la notable serie de relativos "antibufones cervantinos", personajes "amuseurs" como Berganza, Vidriera y la misma Preciosa, pero que por razones morales rechazan entrar de lleno en la truhanería viciosa o profesional (La bourle et son interprétation, p. 313).

${ }^{59}$ Cancionero, ed. Emilio Cotarelo y Mori, Madrid, 1900, p. 87. El vidrio sin protección se consideraba entonces como expresión tópica de la idea de peligro: "Qué andáis más peligroso / que redoma sin vasera"' lo dijo ya Juan de Mena, atacando a cierto miles gloriosus (Alberto Várvaro, Premesse ad un'edizione critica delle poesie minori di Juan de Mena, Napoli, 1964, p. 101). Sobre la olla de barro como símil de la fragilidad biológica del hombre y sus orígenes bíblicos, Alfred G. Garvin, "The Man Who Thought Himself made of Glass and Certain Related Images", SPh, 67 (1970), p. 399.

${ }^{60}$ Francisco Márquez Villanueva, “Jewish 'Fools' of the Spanish Fifteenth Century", $H R, 50$ (1982), 385-409; Stephen Gilman, "A Generation of Conversos", RPh, 33 (1979), 87-101. 
confrontación de dos Españas: por el momento nada más que un vidrio indefenso entre puños amenazadores. Al tensar, creadora, el lenguaje hasta su mismo punto de ruptura, la buenaventura de La gitanilla no hacía sino reflejar la situación de una sociedad en trance, a su vez, de interno y catastrófico desgarro.

Harvard University

Francisco Márquez Villanueva 